\title{
Choice Model and Influencing Factor Analysis of Travel Mode for Migrant Workers: Case Study in Xi'an, China
}

\author{
Hong Chen, Zuo-xian Gan, and Yu-ting He \\ School of Highway, Chang'an University, Xian 710064, China \\ Correspondence should be addressed to Zuo-xian Gan; gump2507@163.com
}

Received 17 July 2014; Accepted 22 September 2014

Academic Editor: Geert Wets

Copyright (C) 2015 Hong Chen et al. This is an open access article distributed under the Creative Commons Attribution License, which permits unrestricted use, distribution, and reproduction in any medium, provided the original work is properly cited.

\begin{abstract}
Based on the basic theory and methods of disaggregate choice model, the influencing factors in travel mode choice for migrant workers are analyzed, according to 1366 data samples of Xian migrant workers. Walking, bus, subway, and taxi are taken as the alternative parts of travel modes for migrant workers, and a multinomial logit (MNL) model of travel mode for migrant workers is set up. The validity of the model is verified by the hit rate, and the hit rates of four travel modes are all greater than $80 \%$. Finally, the influence of different factors affecting the choice of travel mode is analyzed in detail, and the inelasticity of each factor is analyzed with the elasticity theory. Influencing factors such as age, education level, and monthly gross income have significant impact on travel choice mode for migrant workers. The elasticity values of education degree are greater than 1 , indicating that it on the travel mode choice is of elasticity, while the elasticity values of gender, industry distribution, and travel purpose are less than 1, indicating that these factors on travel mode choice are of inelasticity.
\end{abstract}

\section{Introduction}

Migrant workers refer to the people who came from the countryside, who used to be farmers, but now work in cities. They are mainly distributed in construction industry, manufacturing industry, accommodation industry, and so forth and are a special labor group in the process of industrialization and urbanization in China. According to statistics, the total amount of migrant workers in China comes to be more than 200 million in 2013, and the proportion of migrant workers in some Chinese cities has reached 20\%. By summing up, the current migrant workers in China have the following features.

(1) Long work hours, worse stability compared to urban residents.

(2) Work on manual labor, with low wages generally.

(3) Relatively difficult living conditions, a relative low quality of life.

(4) Level of consumption being generally low, but the new generation of them maybe not so.
(5) Middle-aged workers often bearing an important economic source of family.

(6) Cultural and recreational activities being dull.

Migrant workers belong to vulnerable groups, and they are different from ordinary citizens in life, work, consumption, and psychology. As a large group, their survival characteristics and behavior characteristics should be analyzed separately, but they are most likely to be ignored in the city, although they are the group who have made enormous contributions to the construction of urban society in China.

In recent years, choice models have proven to be very effective tools for policy analysis and evaluation in transportation research and there have been numerous efforts from the research on the travel characteristics of the urban residents, but not limited to work by Ahern and Tapley [1], Bastin et al. [2], Beuthe and Bouffioux [3], and Bliemer et al. $[4,5]$. A recent study performed by Nielsen pointed out that travel mode choice relates to not only the level of service, but also the individual attributes and travel characteristics [6]. Bowman and Ben-Akiva proposed a discrete choice model 
based on individual activities and travel plans to predict urban passenger travel, combined with the 1991 Boston travel survey data as an example, and the result shows that the expected maximum utility affects travelers on travel mode choice [7]. As the disaggregate model was used to estimate the joint selection model of residential choice and travel mode choice, a joint choice model of residence and travel mode based disaggregate model could be established $[8$, 9]. Ivanova established travel mode choice model with the multinomial logit model and layered logit model [10]. Saleh and Farrell built departure time choice model of work and nonwork travel for residents in the city center of Edinburgh and analyzed the changes of departure time when charging congestion fee [11].

Choice behavior is a complex decision making process; many factors influence the demand for people's travel choice. As discussed in the example investigated by Hess at al., a host of factors, including flight frequency, flexible tickets, capacity, schedule delay, would affect people's choice of airline [12]. Kwigizie et al. select individual attributes, socioeconomic attributes, and travel characteristics and analyzed the probability of travel mode with cross hierarchical model [13]. Bel has looked at the influence of nonmonetary factors, such as travel time, on rail demand on interurban trip [14]. According to the studies of Vega and Reynolds-Feighan and Hess et al., the utility systems of residence, travel mode, and departure time should be the function of travel time, travel cost, real estate prices, and travelers' economic and social attributes $[15,16]$. Moreover, the land use attributes and travel time are important in explaining the variation in mode choice for medium-distance travel and longer-distance travel when the socioeconomic characteristics of travelers are fixed [17].

The results of research above had good theoretical guidance to carry out the construction of urban traffic scientifically and reasonably, because the travel law of urban residents is fully considered in the transportation planning and urban construction. However, various efforts above focused on the research of the ordinary city residents, and the study of migrant workers is rare, especially in China, where thousands of migrant workers live. Since the attention and studies on migrant workers of researchers are not enough, there is a lack of modeling and analysis of their travel mode choice in urban traffic planning. The paper takes the migrant workers in Xian as an example and obtains the basic data through the questionnaire survey. Then, the choice model of travel mode for migrant workers is established based on MNL model, while the individual attribute and travel attribute are taken as utility variables. Finally, the sensitivity of each factor affected on travel mode choice is analyzed by elasticity theory. Thus, the current studies focusing on travel mode choice of migrant workers in Xi'an will provide a reference and theoretical guidance for formulation of rational transport policy.

\section{Questionnaire Survey}

2.1. Selection of Survey Sample. In early October 2013, we conducted a survey for the travel mode choice of migrant

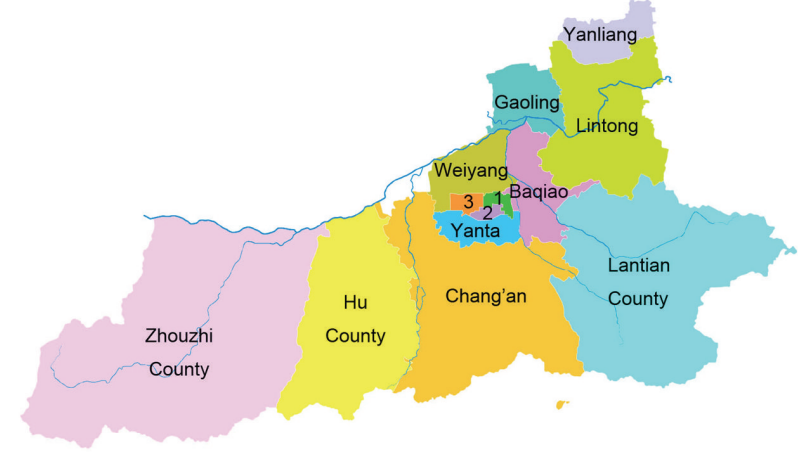

(1) Xincheng

(2) Beilin

(3) Lianhu

FIGURE 1: Geographical distribution of different administrative area in Xian.

workers in Xian, which consisted of questionnaire survey and site visits. Due to the lack of accurate statistics and the distribution of profession about migrant workers in Xian, we selected several major industrial areas and industries where gathered a large number of migrant workers to carry out the survey, according to the actual distribution of them in Xian. Thirty locations in six major districts (Xincheng, Beilin, Lianhu, Baqiao, Weiyang, and Yanta are the six major districts in Xi'an, as shown in Figure 1) of Xi'an are identified as the sites of a questionnaire survey, which are located in urban villages, community streets, labor market located near 2nd-ring road, 3rd-ring road, and beltway. At the same time, construction, manufacturing, transportation, housekeeping and other industries are chosen as survey sites. At the beginning of the survey, 1500 questionnaires are planned to distribute, but 1397 copies of questionnaires are randomly distributed in this survey in fact. After the statistics and collation of the 1397 questionnaires, 1366 questionnaires are valid by judgment, and the effective rate is $97.8 \%$.

2.2. Basic Statistical Data. The content of the survey covers mainly the sex ratio, age structure, educational level, the average monthly gross income, and occupation. After the statistics on the survey data, there are 1000 men and 366 women, respectively account for $73.2 \%$ and $26.8 \%$ percentage of all respondents in the survey. Specific basic properties are shown in Figure 2.

\section{Disaggregate Model of Travel Mode Choice for Migrant Workers}

3.1. Description of Disaggregate Model. The theoretical basis of disaggregate model is a hypothesis that travelers seek to maximize the effectiveness in the selection of travel mode. To overcome many shortages of aggregate model, disaggregate model and its derivatives are widely used. The assumption of disaggregate model is that travelers would choose the travel mode for the greatest utility under certain conditions, and the 

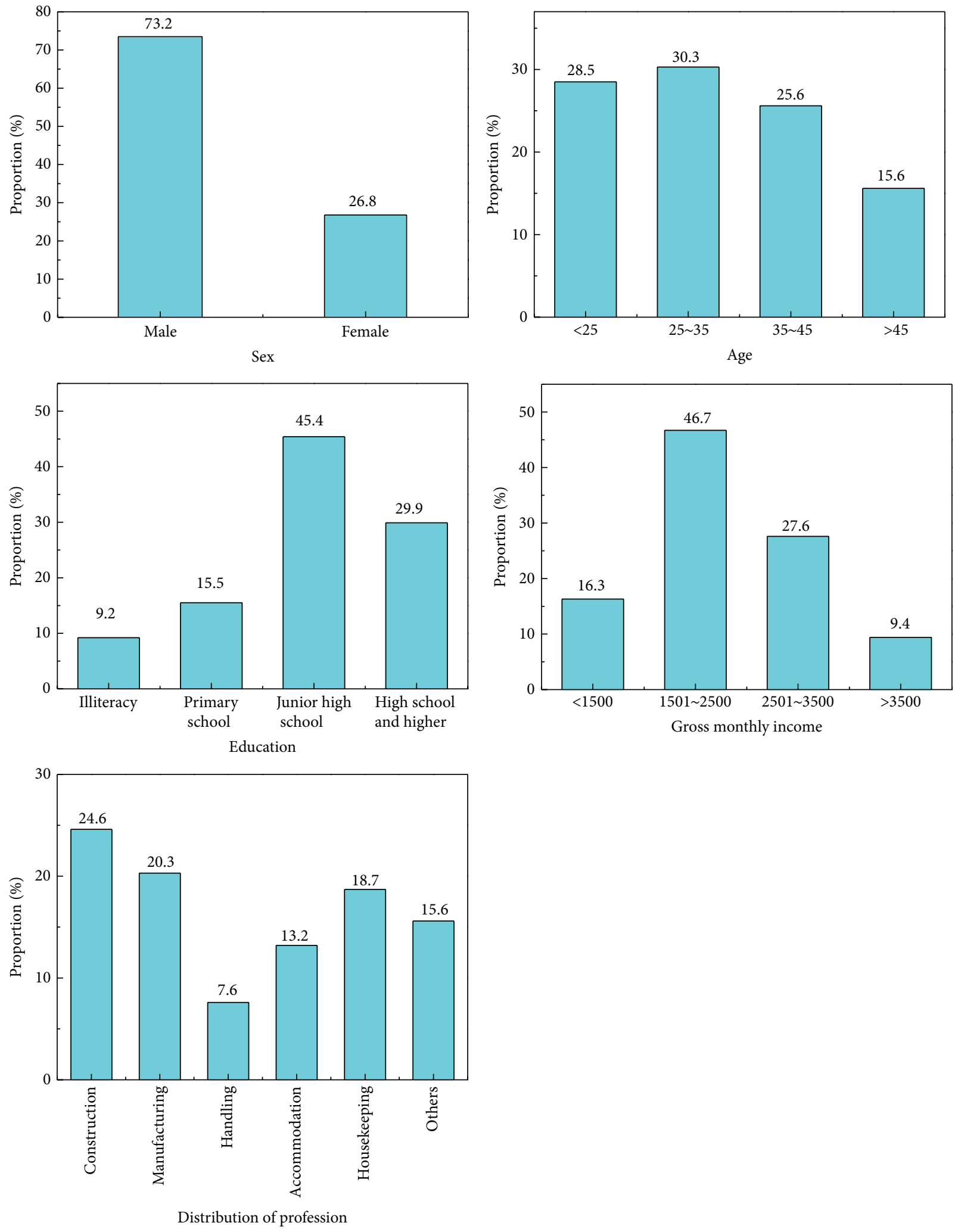

FIgURE 2: Individual attribute data of migrant workers. 
TABLE 1: Determination of influencing factors.

\begin{tabular}{|c|c|c|c|}
\hline The category of factors & Influencing factors & Variable & Explanation \\
\hline \multirow{5}{*}{ Individual attribute } & Sex & $X_{1}$ & Male $=1$, female $=0$ \\
\hline & Age & $X_{2}$ & $\begin{array}{l}\text { Age under } 25=0 \text {, age between } 25 \text { and } 35=1 \text {, age between } 35 \text { and } 45=2 \text {, } \\
\text { and age over } 45=3 \text {. }\end{array}$ \\
\hline & Education & $X_{3}$ & $\begin{array}{l}\text { Illiteracy }=0 \text {, primary school }=1 \text {, junior high school }=2 \text {, and high } \\
\text { school and higher }=3 \text {. }\end{array}$ \\
\hline & Gross monthly income & $X_{4}$ & $\begin{array}{l}\text { Income under } 1500=0 \text {, income between } 1501 \text { and } 2500=1 \text {, income } \\
\text { between } 2501 \text { and } 3500=2 \text {, and income over } 3501=3 .\end{array}$ \\
\hline & Distribution of profession & $X_{5}$ & $\begin{array}{l}\text { Construction industry }=1 \text {, manufacturing industry }=2 \text {, handling } \\
\text { Industry }=3 \text {, accommodation industry }=4 \text {, housekeeping industry }=5 \text {, } \\
\text { and others }=0 \text {. }\end{array}$ \\
\hline \multirow{3}{*}{ Travel attribute } & Travel distance & $X_{7}$ & $0 \sim 1 \mathrm{~km}=0,1 \sim 3 \mathrm{~km}=1,3 \sim 5 \mathrm{~km}=2,5 \sim 10 \mathrm{~km}=3$, and over $10 \mathrm{~km}=4$ \\
\hline & Travel purpose & $X_{8}$ & Work $=1$, entertainment and shopping $=2$, and others $=0$ \\
\hline & Transfer or not & $X_{9}$ & Yes $=1$, no $=0$ \\
\hline
\end{tabular}

utility function of it is composed by fixed term and random term. The formulas are as follows:

$$
\begin{gathered}
U_{\text {in }}=V_{\text {in }}+\varepsilon_{i n}, \\
V_{\text {in }}=\sum_{k=1}^{K} \theta_{k} X_{\text {ink }},
\end{gathered}
$$

where $U_{i n}$ is utility value of the $i$ th travel mode chosen by the $n$th traveler; $V_{\text {in }}$ is the fixed term of utility value $U_{i n} ; \varepsilon_{i n}$ is the random term of utility value $U_{i n} ; K$ is the number of factors (which is also called characteristic variables) affected on the mode choice of travelers; $\theta_{k}$ is the undetermined coefficient; $X_{i n k}$ is the $k$ th factor of the $i$ th travel mode chosen by the $n$th traveler.

3.2. Establishing of MNL Model. If the random term $\varepsilon_{i n}$ in formula (1) obeys Gumbel distribution and all variables are independent from each other, the probability $P_{i n}$ of the $i$ th travel mode chosen by the $n$th traveler is given by the following formula:

$$
P_{i n}=\frac{e^{V_{i n}}}{\sum_{i=1}^{N} e^{V_{i n}}},
$$

where $N$ is the sum number of alternative travel mode for travelers.

At this time, the model evolves to multinomial logit (MNL) model, which is the common form in disaggregate theory. MNL model is characterized by having simple mathematical form, easy to be understand and so on, therefore, it is one of the most widely used and most mature model in the disaggregate theory.

\subsection{Determination of the Alternative Parts and Influencing} Factors. According to the survey of migrant workers in Xi'an, their travel modes are mainly made up of four kinds of modes, which are walking, bus, subway, and taxi. Therefore, the four kinds of travel mode are the alternative parts of the choice
TABLE 2: The calibration results of influencing factors.

\begin{tabular}{lccc}
\hline $\begin{array}{l}\text { Influencing } \\
\text { factors }\end{array}$ & $\begin{array}{c}\text { Parameter } \\
\text { values }\end{array}$ & $\begin{array}{c}\text { Standard } \\
\text { deviation }\end{array}$ & $t$-test \\
\hline Sex & 0.8368 & 0.2065 & 6.9582 \\
Age & 1.2735 & 0.0739 & 7.2204 \\
Education & 1.0689 & 0.0847 & 4.8258 \\
$\begin{array}{l}\text { Gross monthly } \\
\text { income }\end{array}$ & 1.1798 & 0.0598 & 3.9213 \\
$\begin{array}{l}\text { Distribution of } \\
\text { profession }\end{array}$ & 0.3721 & 0.0643 & 5.7877 \\
Travel distance & 0.8294 & 0.0482 & 8.9169 \\
Travel purpose & 0.3931 & 0.0871 & 4.5145 \\
Transfer or not & -2.5610 & 0.0931 & -6.0268 \\
\hline
\end{tabular}

model. To the need of calculation, walking is treated as 0 , and bus as 1 , subway as 2 , and taxi as 3 in the choice model of travel mode for migrant workers.

Influencing factors in the model should be determined according to the survey objectives and the current situation. Considering migrant workers trip characteristics and MNL model characteristics, we divided the influencing factors into individual attribute and travel attribute, influencing factors of these two attributes and the explanation for them are shown in Table 1.

\section{Calibration and Verification of the Model}

4.1. Calibration of Influencing Factors. The utility function of MNL model is often calibrated by maximum likelihood estimation method; namely, the estimated values of the prediction parameters are obtained by seeking to maximize the number of maximum likelihood estimation of the function. The calibration result obtained through transportation software SPSS is shown in Table 2.

The absolute value of $t$-test for each influencing factor is greater than 1.96 from that shown in Table 2. According to 
TABLE 3: The values of influencing factors.

\begin{tabular}{lcccc}
\hline Influencing factors & Variable & Walking & Bus & Subway \\
\hline Sex & $X_{1}$ & 0.8368 & & 0.8368 \\
Age & $X_{2}$ & 1.2735 & 1.2735 & 1.0689 \\
Education & $X_{3}$ & 1.0689 & & 1.0689 \\
Gross monthly income & $X_{4}$ & 1.1798 & 0.3721 & 1.1798 \\
Distribution of profession & $X_{5}$ & 0.3721 & 0.8294 & 0.3721 \\
Travel distance & $X_{6}$ & & & 0.3931 \\
Travel purpose & $X_{7}$ & 0.3931 & -2.5610 & -2.5610 \\
Transfer or not & $X_{8}$ & & & 0.8294 \\
\hline
\end{tabular}

statistical theory, it has $95 \%$ certainty that the influence of influencing factors affected on alternative parts is significant, when the absolute value of $t$-test is greater than 1.96. Thus, the influencing factors had a significant effect on the travel mode choice for migrant workers. Meanwhile, the coefficient of determination $\rho^{2}$ can be used to judge the fit of the model [18], in which $\rho^{2} \in(0,1)$. The degree of fitting of the model established is considered good when $\rho^{2}$ is between 0.2 and 0.4 in the actual judgment of the disaggregate model. $\rho^{2}$ of the model established in the paper is 0.2863 ; therefore, we fully believe the degree of fitting of the model is good.

According to the test above, the calibrations of parameters in the model are correct. For the four kinds of travel mode, the value of different influencing factors is shown in Table 3.

If the random term in the utility function is not being considered, each utility function for different kinds of travel mode got by Table 3 is shown as follows:

$$
\begin{aligned}
V_{\text {walk }}= & 0.8368 X_{1}+1.2735 X_{2}+1.0689 X_{3}+1.1798 X_{4} \\
& +0.3721 X_{5}+0.3931 X_{7}, \\
V_{\text {bus }}= & 1.2735 X_{2}+1.0689 X_{3}+0.3721 X_{5}+0.8294 X_{6} \\
& -2.5610 X_{8}, \\
V_{\text {metro }}= & 0.8368 X_{1}+1.0689 X_{3}+1.1798 X_{4}+0.3721 X_{5} \\
& +0.3931 X_{7}-2.5610 X_{8}, \\
V_{\text {taxi }}= & 0.8368 X_{1}+1.2735 X_{2}+1.1798 X_{4}+0.8294 X_{6} .
\end{aligned}
$$

4.2. Verification of the Model. The MNL model could be verified by hit rate (HitR), which refers to the fit between the actual choice result of travel mode and the predicted choice result of that obtained by using the model. The calculation steps of HitR are shown as follows.

Step 1 . The parameter values $\theta_{k}$ obtained by the MNL model above and the corresponding value $X_{\text {ink }}$ of the original variable are substituted into the probability formula (3); then the predicted probability of mode choice of traveler $n$ can be obtained.
Step 2. Assuming traveler $n$ has chosen the travel mode, the predicted probability of which is the maximum, we defined $\hat{\delta_{i n}}$ as follows:

$\hat{\delta_{i n}}= \begin{cases}1 & P_{\text {in }} \text { is the maximum in four kinds of mode } \\ 0 & \text { other. }\end{cases}$

Step 3. The calculation of $S_{\text {in }}$ is $S_{\text {in }}=1$ when the actual choice result is consistent with the predicted results; $S_{\text {in }}=0$ when they are inconsistent:

$$
S_{i n}=\left\{\begin{array}{ll}
1 & \delta_{i n}=\hat{\delta_{i n}} \\
0 & \delta_{\text {in }} \neq \hat{\delta_{i n}}
\end{array} .\right.
$$

Step 4. The calculation of integral hit rate HitR and the hit rate $\mathrm{HitR}_{i}$ of the $i$ th mode is

$$
\begin{gathered}
\text { HitR }=\frac{\sum_{n=1}^{N} \sum_{i \in A_{n}} S_{i n}}{\sum_{n=1}^{N} J_{n}}, \\
\text { HitR }_{i}=\sum_{n=1}^{N} \frac{S_{i n}}{N_{i}},
\end{gathered}
$$

where $J_{n}$ is the total number of travel mode chosen by the $n$th traveler; $N_{i}$ is the total number of people who may choose travel mode $i$.

The integral hit rate and the hit rate for the different choice mode of the MNL model for migrant workers, obtained through the calculation of hit rate above, are shown in Table 4.

Relatively speaking, the hit rate of taxi is lower than the other three travel modes, it is mainly because of taxi data in the sample is small, which results in decreasing the hit rate. However, the hit rates of four travel modes are all greater than $80 \%$ and the integral hit rate is $91.4 \%$, indicating that the model and the calibration of the parameters in the model are effective.

\section{Sensitivity Analysis of Different Influencing Factors}

Sensitivity analysis refers to the degree of change of the final predicted result, while an influencing factor has changed 
TABLE 4: The hit rate of the MNL model for migrant workers.

\begin{tabular}{|c|c|c|c|c|c|}
\hline \multirow{2}{*}{ Actual value } & \multicolumn{4}{|c|}{ Predictive value } & \multirow{2}{*}{ Hit rate } \\
\hline & Walking & Bus & Subway & Taxi & \\
\hline Walking (639) & 595 & 32 & 12 & 0 & $93.1 \%$ \\
\hline Bus (482) & 29 & 430 & 17 & 6 & $89.2 \%$ \\
\hline Subway (176) & 2 & 8 & 162 & 4 & $91.9 \%$ \\
\hline Taxi (68) & 0 & 2 & 7 & 59 & $86.6 \%$ \\
\hline The proportion of travel mode in prediction & $45.8 \%$ & $34.6 \%$ & $14.5 \%$ & $5.1 \%$ & $91.4 \%$ \\
\hline
\end{tabular}

TABLE 5: Average value and elasticity value of individual attribute.

(a)

\begin{tabular}{lccccccccc}
\hline \multirow{2}{*}{ Travel mode } & \multicolumn{2}{c}{ Sex } & \multicolumn{3}{c}{ Age } & \multicolumn{3}{c}{ Education } \\
& Overall average & Average & Elasticity & Overall average & Average & Elasticity & Overall average & Average & Elasticity \\
\hline Walking & & 0.6854 & 0.3052 & & 1.5420 & 1.0451 & & 1.7921 & 1.0194 \\
Bus & \multirow{2}{*}{0.732} & 0.8003 & 0.4331 & \multirow{2}{*}{1.283} & 1.1041 & 0.9093 & 1.960 & 2.0034 & 1.3849 \\
Subway & & 0.7034 & 0.5128 & & 0.9296 & 1.0314 & 2.4020 & 2.2370 \\
Taxi & & 0.7590 & 0.6033 & & 1.0344 & 1.2512 & 2.1101 & 2.1424 \\
\hline
\end{tabular}

(b)

\begin{tabular}{lcccccc}
\hline \multirow{2}{*}{ Travel mode } & \multicolumn{2}{c}{ Gross monthly income } & \multicolumn{3}{c}{ Distribution of profession } \\
& Overall average & Average & Elasticity & Overall average & Average & Elasticity \\
\hline Walking & & 1.2712 & 0.7981 & & 2.2621 & 0.448 \\
Bus & \multirow{2}{*}{1.301} & 1.295 & 0.9881 & 2.343 & 2.4413 & 0.5875 \\
Subway & & 1.3861 & 1.4248 & & 2.387 & 0.7739 \\
Taxi & & 1.4032 & 1.5725 & & 2.2854 & 0.8078 \\
\hline
\end{tabular}

in the model, which not only can be used to understand the interaction between travel mode choices and influencing factors, but also can evaluate qualitatively and quantitatively the impact on the model result when variables changed in the model.

According to the theory of disaggregate model, when the $k$ th influencing factors changed, the value of elasticity of the $i$ th mode, chosen by the traveler, can be calculated as follows:

$$
E=\left(1-P_{i}\right) \theta_{k} \bar{X}_{i n k}
$$

where $P_{i}$ is the choice probability of travel mode $i$, namely, the actual share of each travel mode; $\theta_{k}$ is the parameter value estimated of $k$ th influencing factors; $\bar{X}_{i n k}$ is the average value of $X_{\text {ink }}$.

5.1. Sensitivity Analysis on Individual Attribute. With the statistical processing of 1336 samples in individual property, we can get the average impact value $\bar{X}_{\text {ink }}$ of five factors such as actual contribution rate of four different travel modes $P_{i}$, gender, age, and so forth. Through the model calibration results in Table 2 , the parameter estimated value $\theta_{k}$ could be obtained. In this way the elasticity values of different factors in different transportation modes can be achieved. The results are shown in Table 5. (The transfer in the paper refers to the transfer between bus and bus, subway and subway, and also bus and subway.)
From Table 5 we can know that the average value of walking and subway is lower than the total average value, indicating that female migrant workers would like to prefer to walking and subway rather than bus and taxi. This may relate to females' travel demand and the investigation climate. The survey is conducted in early October and the weather is still hot in Xian. Since women put more emphasis to travel conditions than men, they always carry a parasol with them and do not like crowds and noisy environment in their trip, and would like to travel on foot or by subway with air conditioner rather than by a sweltering bus in hot weather. These four transportation elasticity values are less than 1, indicating that the influence on travel mode choice of the different sex is lack of elasticity, namely, the difference of sex has few impacts on travel mode choice.

The average value of travelers' age in walking is obviously higher than the overall average value, indicating that most of the older migrant workers would like to choose walking as a way to travel. This is mainly because, compared to young migrant workers, the older migrant workers more cherish their earned money, and they often have parents and children to support so that their family economic burden is relatively heavy to bear, while the younger migrant workers' economic pressure is lower and their concept of consumption is no longer conservative. Sometimes they value the service quality of travel mode more than the price of that in trip. In these four corresponding elasticity values, only bus is little lower than 1 . It indicated that the age variation had less impact on choosing 
TABLE 6: Average value and elasticity value of travel attribute.

\begin{tabular}{|c|c|c|c|c|c|c|c|c|c|}
\hline \multirow{2}{*}{ Travel mode } & \multicolumn{3}{|c|}{ Travel distance } & \multicolumn{3}{|c|}{ Travel purpose } & \multicolumn{3}{|c|}{ Transfer or not } \\
\hline & Overall average & Average & Elasticity & Overall average & Average & Elasticity & Overall average & Average & Elasticity \\
\hline Walking & \multirow{4}{*}{1.2335} & 1.182 & 0.5217 & \multirow{4}{*}{1.0374} & 1.0172 & 0.2128 & \multirow{4}{*}{0.0580} & 0 & 0 \\
\hline Bus & & 1.1911 & 0.6389 & & 1.0221 & 0.2598 & & 0.1420 & -0.2352 \\
\hline Subway & & 1.262 & 0.9119 & & 1.1082 & 0.3795 & & 0.0622 & -0.1388 \\
\hline Taxi & & 1.3402 & 1.0558 & & 1.1522 & 0.4302 & & 0 & 0 \\
\hline
\end{tabular}

the bus. The elasticity value of taxi is highest, which means that the age variation had the most impact on choosing taxi. Taxi fare is more expensive than other travel modes in reality, which is consistent with the age characteristics.

The average value of walkers' education in Table 5 is the lowest. This may be because people with lower education often have lower income, so the transportation fee they could burden is less. The highest average value of education degree is subway rather than the taxi. This is because that the ticketing process as well as entering and exiting the station of taking a subway is more complicated than that of other travel mode, so migrant workers with lower education would prefer traditional bus and taxi rather than the subway. The elasticity values of four travel modes are greater than 1, indicating that the variation of education degree had a more significant impact on trip mode choice.

There is a large difference between bus and metro in monthly average income situation from Table 5 . Both of them are public transportation tools, however, most bus fare in Xi'an are 1 yuan, and it can be half-price concession by using a transportation card; while the ticket price of Xian subway starts from 2 yuan, 3 yuan for $7-10$ stations, and 4 yuan for more than 11 stations, and with the use of card the price can be $30 \%$ off, which means the lowest price of subway fee needs 1.4 yuan. Since taking a bus is much cheaper than subway, the migrant workers with low income prefer bus as their travel tool. The elasticity value of walking and taking a bus is less than 1 , which indicated that variation of monthly income status has less influence on both walking and bus, especially walking. This is mainly because walking is different from the other travel methods, and there is no need to use transportation tools when travel distance is not far, and people from different income level have the possibility in choosing walking. But when travel distance becomes farther, people with different income may choose other different travel modes (which can also be seen from the elasticity value of walking in travel distance). The average value of taxi is the largest in monthly income status, which also met the reality. At the same time its elasticity value is greater than 1 , indicating that changes in income will affect the choosing of taxi significantly.

The average value of industrial distribution on walking is the minimum value. In accordance with assignment regulations of industrial distribution in Table 5, we could find that people travel on foot are concentrated on construction, manufacturing industries. In reality, most of the construction and manufacturing industries are located at the outskirts of a city, such as out of the 2nd-ring or 3rd-ring of Xi'an in this investigation, where far away from downtown area.
So enterprises and factories usually furnish staff quarters or house rented near from the workplace for staffs, travel mode is not needed when people go to work. The accommodation, housekeeping, and other service industries are mostly located in urban areas and even some prosperous sections. Migrant workers in these industries prefer to live at some distance away from the workplace to save money on accommodation, which results in a higher proportion of choosing buses than that in construction and manufacturing fields. However, all elasticity values of these four travel modes are less than 1 , which indicated that there is a lack of elasticity about the industrial distribution impact on travel mode choice. Because migrant workers' travel mode choice are mainly affected by their education, gross monthly income, travel distance, rather than their occupation.

5.2. Elasticity Analysis on Travel Attribute. The calculation method and elasticity analysis process for travel attribute are same with that of individual attribute. The elasticity of travel attribute is shown in Table 6.

The sequence order of travel distance for four mode travelers used is walking $<$ bus $<$ subway $<$ taxi, and this order is consistent with the actual behavior when travelers face different travel distance. Only the elasticity value of taxi is greater than 1 among four travel modes, indicating that the impact of the change in travel distance on the choice of taxi is slightly significant, while the impact on the other travel mode is not significant. From the survey and the conversation with migrant workers, we know that most of migrant workers thought the value of expenses is greater than the value of time in travel, and they are more sensitive about the price level than the travel distance. This also can be from the comparison of elasticity value between monthly gross income and travel distance.

The assignment of travel purpose in Table 6 is a human decision in the paper, which did not have the regularity and size indeed. Thus, the average values of travel purpose have no practical significance from the view of mathematics, and they are regarded as a bridge to calculate the elasticity values. The elasticity values of the four travel modes are all less than 1 , indicating that the change of travel purpose does not have a significant impact on the choice of travel mode for migrant workers. It is that there is no large or small about the evaluation of different travel purpose, so the influence on the travel mode choice cannot be quantified, the average values merely reflected the change of travel purpose has a certain influence on the travel mode choice.

The overall average of transfer is far less than 1 , and the important reason of which is that the number of people who 
have to transfer in their trip is small (Transfer $=1$, Not transfer $=0$, see Table 1 ), and there are only 78 persons in this survey. Traveling on foot or by taxi do not involve the transfer or not, so the average value and elasticity value of walking and taxi are 0 . The average value of transfer by bus is greater than that by subway, indicating that migrant workers in Xi'an prefer to transfer with bus more than to transfer with subway. This matches current situation that the transfer process with subway is more complex than that of bus, and there are only two subway lines in Xian for now, the places subway could reach are not a lot, and therefore transfer with subway is less convenient than that of bus. The elasticity values of bus and subway are less than 1 in the paper; the reason of that is that the average value is too small.

\section{Conclusions}

In this paper, the choice model of travel mode for migrant workers in China is established based on utility maximization theory. According to the actual characteristics of travel choice for migrant workers, the four common kinds of travel mode for migrant workers including walking, bus, subway, and taxi are identified as the alternative parts in the model. Then, we identify two categories of factors: individual attribute and travel attribute, which contained eight kinds of influential factors, such as sex, age, and travel distance.

The absolute value of $t$-test for each influencing factor is greater than 1.96 in the paper, so we have reason to believe that all the influencing factors we chose in the paper had a significant effect on the travel mode choice for migrant workers in China. At the same time, the degree of fitting of the model is good, because the coefficient of determination $\rho^{2}$ in the MNL model is 0.2386 . Hit rate (HitR) is also used to verify the validity of the choice model for travel mode. From the view of the result of HitR calculated, the hit rates of four travel modes are all greater than $80 \%$ and the integral hit rate is $91.4 \%$, which also provides the basis for the mode to accurately reflect the travel choice behavior of migrant workers and the influence of influencing factors affected on their choice of travel mode.

The elastic theory is introduced to analyse the elasticity of each factor in the model. The result shows that age, education, and monthly gross income have significant impact on the choice of travel mode for migrant workers, and, especially, the influence of education impact on four kinds of travel mode is flexible, the elasticity values of which are all greater than 1 . But the influence of sex, distribution of profession, travel purpose on the choice of travel mode for migrant workers is slight, and their changes are lack of elasticity in the travel mode choice for migrant workers.

With not only the established model and its analysis but also the communication with migrant workers and their opinions about traffic in the survey, we can propose some suggestions to facilitate their travel. Migrant workers' income is generally low; the government can implement policies for them to encourage consumption on travel, and do the traffic guidance work well to reduce the complexity of transfer. By making urban transportation more equitable distribution, migrant workers can enjoy better urban transportation.
In conclusion, although our survey involves only a part of the migrant workers in Xi'an and only eight influencing factors are considered in the model, an effective model which can reflect the reality of travel choice behavior of migrant workers in China is established in the paper. The authors believe that the conclusion in the paper can be used to support traffic planning and policy making strategy, which will help the cities with a large number of migrant workers in China to consider the travel law of migrant workers during the traffic planning and urban construction.

\section{Conflict of Interests}

The authors declare that there is no conflict of interests regarding the publication of this paper.

\section{Acknowledgments}

This work is financially supported by the National Natural Science Foundation of China (Grant no. 51208054). The authors would like to thank Dr. Long-fei Wang and Dr. Min Zhang for their suggestion for the paper and all people involved in the survey for their careful and meticulous work.

\section{References}

[1] A. A. Ahern and N. Tapley, "The use of stated preference techniques to model modal choices on interurban trips in Ireland," Transportation Research Part A: Policy and Practice, vol. 42, no. 1, pp. 15-27, 2008.

[2] F. Bastin, C. Cirillo, and P. L. Toint, "Application of an adaptive Monte Carlo algorithm to mixed logit estimation," Transportation Research Part B: Methodological, vol. 40, no. 7, pp. 577-593, 2006.

[3] M. Beuthe and C. Bouffioux, "Analysing qualitative attributes of freight transport from stated orders of preference experiment," Journal of Transport Economics and Policy, vol. 42, no. 1, pp. 105$128,2008$.

[4] M. C. J. Bliemer, J. M. Rose, and D. A. Hensher, "Efficient stated choice experiments for estimating nested logit models," Transportation Research Part B: Methodological, vol. 43, no. 1, pp. 19-35, 2009.

[5] M. C. J. Bliemer and J. M. Rose, "Construction of experimental designs for mixed logit models allowing for correlation across choice observations," Transportation Research Part B: Methodological, vol. 44, no. 6, pp. 720-734, 2010.

[6] O. A. Nielsen, "A stochastic transit assignment model considering differences in passengers utility functions," Transportation Research Part B: Methodological, vol. 34, no. 5, pp. 377-402, 2000.

[7] J. L. Bowman and M. E. Ben-Akiva, "Activity-based disaggregate travel demand model system with activity schedules," Transportation Research A: Policy and Practice, vol. 35, no. 1, pp. 1-28, 2000.

[8] D. A. Hensher and W. H. Greene, "Specification and estimation of the nested logit model: alternative normalisations," Transportation Research Part B: Methodological, vol. 36, no. 1, pp. 1-17, 2002.

[9] D. A. Hensher and J. M. Rose, "Development of commuter and non-commuter mode choice models for the assessment 
of new public transport infrastructure projects: a case study," Transportation Research Part A: Policy and Practice, vol. 41, no. 5, pp. 428-443, 2007.

[10] O. Ivanova, "A note on the consistent aggregation of nested logit demand functions," Transportation Research Part B: Methodological, vol. 39, no. 10, pp. 890-895, 2005.

[11] W. Saleh and S. Farrell, "Implications of congestion charging for departure time choice: work and non-work schedule flexibility," Transportation Research A: Policy and Practice, vol. 39, no. 7-9, pp. 773-791, 2005.

[12] S. Hess, T. Adler, and J. W. Polak, "Modelling airport and airline choice behaviour with the use of stated preference survey data," Transportation Research Part E: Logistics and Transportation Review, vol. 43, no. 3, pp. 221-233, 2007.

[13] V. Kwigizie, D. Chimba, and T. Sando, "A cross-nested logit model for trip type-mode choice: an application," Advances in Transportation Studies, vol. 2011, no. 23, p. 29, 2011.

[14] G. Bel, "Changes in travel time across modes and its impact on the demand for inter-urban rail travel," Transportation Research Part E: Logistics and Transportation Review, vol. 33, no. 1, pp. 43-52, 1997.

[15] A. Vega and A. Reynolds-Feighan, "A methodological framework for the study of residential location and travel-to-work mode choice under central and suburban employment destination patterns," Transportation Research Part A: Policy and Practice, vol. 43, no. 4, pp. 401-419, 2009.

[16] S. Hess, A. Daly, C. Rohr, and G. Hyman, "On the development of time period and mode choice models for use in large scale modelling forecasting systems," Transportation Research Part A: Policy and Practice, vol. 41, no. 9, pp. 802-826, 2007.

[17] N. Limtanakool, M. Dijst, and T. Schwanen, "The influence of socioeconomic characteristics, land use and travel time considerations on mode choice for medium- and longer-distance trips," Journal of Transport Geography, vol. 14, no. 5, pp. 327-341, 2006.

[18] D. McFadden, "Conditional logit analysis of qualitative choice behavior," in Frontiers of Econometrics, P. Zarembka, Ed., pp. 105-142, Academic Press, New York, NY, USA, 1973. 


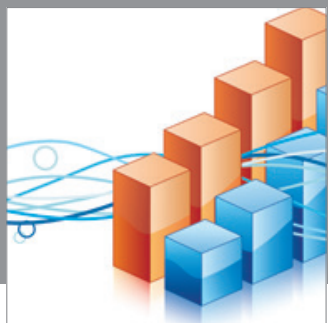

Advances in

Operations Research

mansans

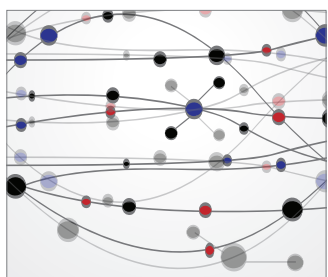

The Scientific World Journal
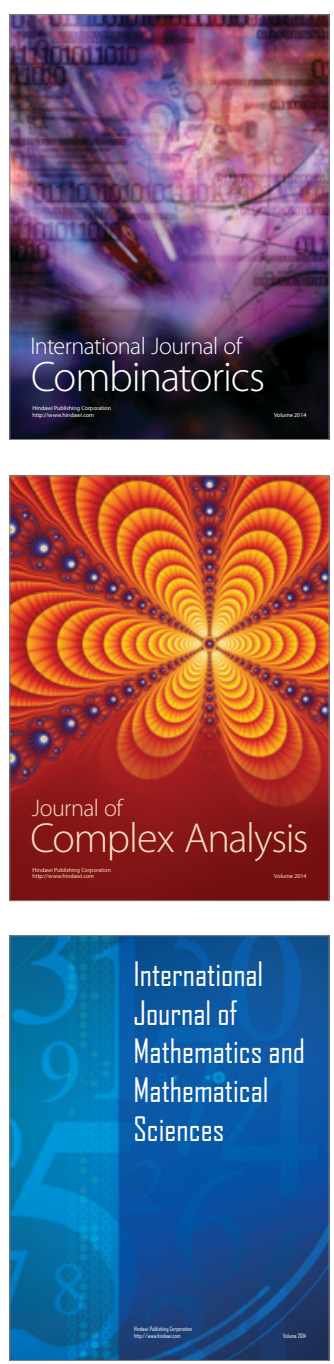
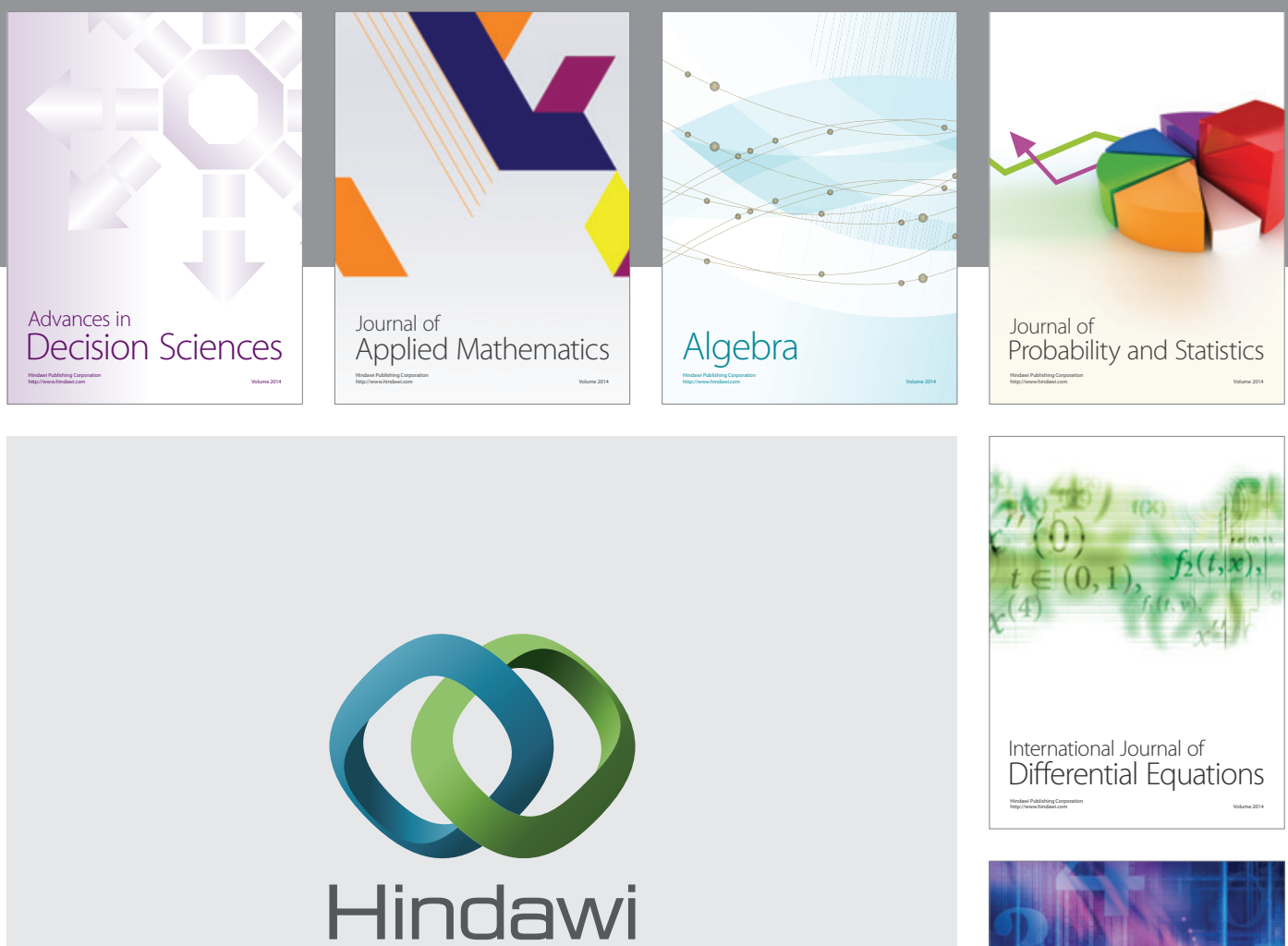

Submit your manuscripts at http://www.hindawi.com
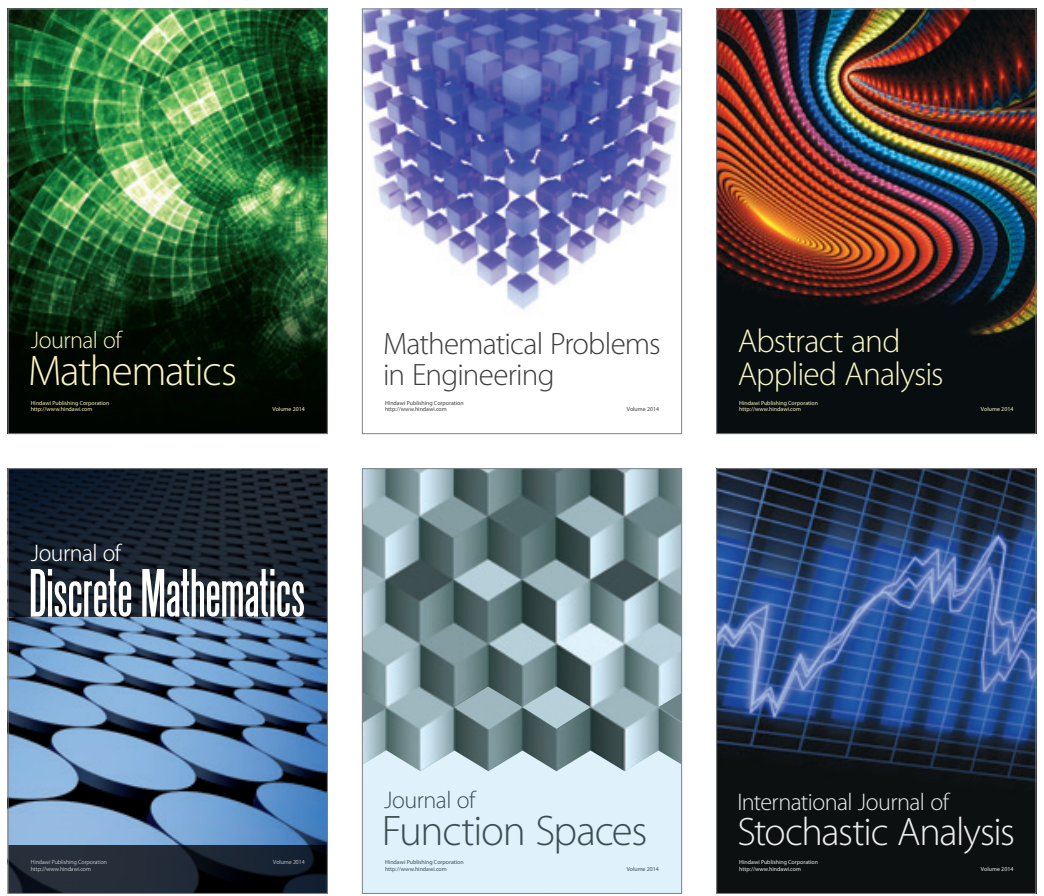

Journal of

Function Spaces

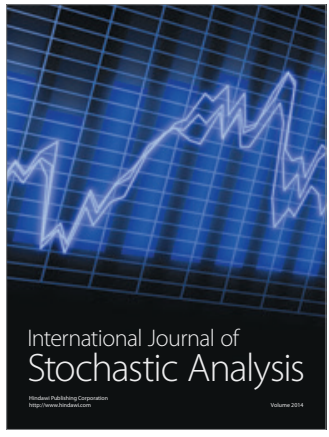

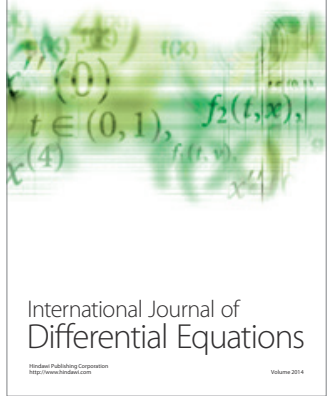
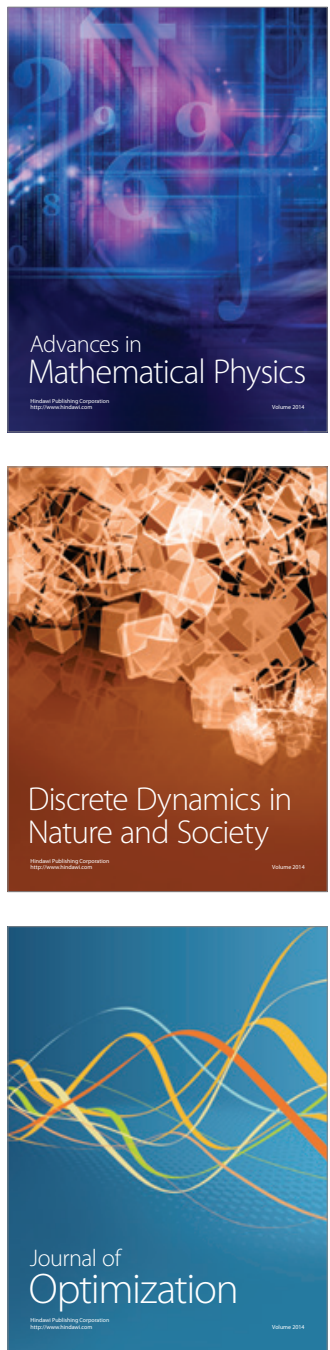